\title{
Efeito anti-proliferativo das infusões de Achyrocline satureioides DC (Asteraceae) sobre o ciclo celular de Allium cepa
}

\author{
Juliana M. Fachinetto ${ }^{1}$, Margarete D. Bagatini ${ }^{2}$, Jaqueline Durigon ${ }^{1}$, \\ Antonio C.F. da Silva ${ }^{1}$, Solange B. Tedesco ${ }^{1 *}$ \\ ${ }^{1}$ Laboratório de Citogenética Vegetal, Departamento de Biologia, Universidade Federal de Santa Maria, Av. \\ Roraima 1000, Cidade Universitária, Camobi, 97105-900, Santa Maria, RS, Brasil, \\ ${ }^{2}$ Curso de Farmácia, Universidade Federal de Santa Maria, Av. Roraima 1000, Cidade Universitária, Camobi, \\ 97105-900, Santa Maria, RS, Brasil
}

\begin{abstract}
RESUMO: Achyrocline satureioides (marcela) é utilizada na medicina popular brasileira, na forma de chá, como tratamento de patologias digestivas e inflamatórias. O efeito anti-proliferativo de infusões de marcela sobre o ciclo celular da cebola foi avaliado, utilizando-se inflorescências de marcela recém coletadas (2005) e após armazenamento por 30 meses (2003). Preparou-se as infusões em duas concentrações: $5,0 \mathrm{mg} / \mathrm{mL}$ (concentração usual como chá) e $20 \mathrm{mg} / \mathrm{mL}$. Utilizaram-se 3 grupos de 6 bulbos de cebola para cada população de marcela. Retirou-se um grupo de bulbos controle de cada população. Todos os bulbos enraizados em água destilada foram transferidos para os extratos de marcela e permaneceram por 24 horas, (os bulbos controle permaneceram em água). As radículas foram coletadas, fixadas em etanol-ácido acético $(3: 1)$ por 24 h e estocadas em álcool 70\%. Foram analisadas 6000 células por grupo de bulbos, e os índices mitóticos calculados submetidos a análise estatística pelo teste $\chi^{2}$ a $5 \%$. Conclui-se que as infusões de marcela possuem ação antiproliferativa sobre o ciclo celular da cebola e que essa ação inibitória da divisão celular aumenta conforme aumento da concentração, bem como após o armazenamento.
\end{abstract}

Unitermos: Achyrocline satureioides, Allium cepa, Asteraceae, Liliaceae, atividade antiproliferativa, índice mitótico, planta medicinal.

\begin{abstract}
Anti-proliferative effect of infusions of Achyrocline satureioides on the Allium cepa cell cycle". Achyrocline saturoides (marcela) is used in Brazilian folk medicine as a tea in the treatment of digestive and inflammatory diseases. The anti-proliferative effect of infusions of marcela on onion cell cycle was evaluated by using the inflorescences of recently collected marcela and after the storage for 30 months. Marcela inflorescences were collected for the infusion preparations in 2003 and in 2005 (used still fresh). We prepared the infusions at two concentrations $5.0 \mathrm{mg} / \mathrm{mL}$ (concentration used as tea) and $20 \mathrm{mg} / \mathrm{mL}$. We used two groups of six onion bulbs for each population of marcela, and one group of bulbs of each population was withdrawn as a control group. All bulbs rooted in distilled water and after they were transferred to the extracts of marcela and they were kept there for 24 hours (control bulbs remained under water). The root tips were collected, after fixed in ethanol acetic acid (3:1) for 24 hours and, stored under alcohol $70 \%$. A total of 6000 cells per group of bulbs was analyzed, and the mitotic indexes were calculated and undergone to statistical analysis by using $\chi^{2}$ at $5 \%$. The conclusions were that the infusions of marcela have anti-proliferative action on the cell cycle of onion and that this inhibitory action on the cell division increases according to the increase of the infusion concentration, after storage as well.
\end{abstract}

Keywords: Achyrocline satureioides, Allium cepa, Asteraceae, Liliaceae, anti-proliferative effect, mitotic index, medicinal plant.

\section{INTRODUÇ̃̃O}

As plantas medicinais são amplamente usadas em vários países para o tratamento de doenças, e no Brasil, a espécie de A. satureioides (Lam.) DC é comumente utilizada na medicina popular na forma de chá para o tratamento de problemas digestivos e inflamatórios.

A. satureioides é uma erva anual da família Asteraceae, possui ramificações de até $1,5 \mathrm{~m}$ de altura coberta de pilosidades brancas. As folhas são alternas, inteiras, sésseis lineares, alanceoladas de até $12 \mathrm{~cm}$ de comprimento por $1,8 \mathrm{~cm}$ de largura. Possui inflorescências do tipo capítulos em dois tipos de flores, reunidas em panículas corimbosas. As flores são amarelo-dourado, as centrais hermafroditas, em número de uma a duas, e as flores marginais são quatro ou cinco. O fruto é do tipo aquênio, glabro e pardo (Castro; Chemale, 1995).

Esta planta é comum no Brasil, ocorrendo de Minas Gerais até o Rio Grande do Sul (De Souza et al., 2002), sendo também conhecida como marcela, marcela- 
do-campo, marcela-da-terra (Almeida,1993), além desses, Lorenzi (2002), cita macela, camomila nacional e macela- amarela.

Infusões das inflorescências de A. satureioides, são muito utilizadas na medicina popular brasileira como um agente digestivo, antiespasmódico, antiinflamatório e hipoglicêmico, para tratar desordens gastrintestinais e reduzir os níveis de colesterol sanguíneo (Ritter et al., 2002; Simões et al., 1984). Em estudo realizado por Vendruscolo et al. (2005), essa espécie aparece entre as 10 medicinais mais utilizadas na forma de chá na medicina alternativa por pessoas de uma comunidade de Porto Alegre, RS.

Estudos experimentais têm demonstrado atividades anti-HIV (Adamoli, 1998), anti-proliferativa (Pessoa, 2000), além de ações antioxidantes (Desmarchelier et al., 1998), anti-herpéticas (Garcia et al., 1999), analgésicas, constipativa e sedativa (Simões et al., 1988), imunomodulatória (Santos et al., 1999), antiviral (Garcia et al., 1995), colerética e hepatoprotetora (Lopez et al., 1996), antimicrobiana (Duarte et al., 2004) e anti-inflamatória (Falcão et al., 2005). Também, $A$. satureioides mostrou atividade mutagênica in vitro contra Salmonella e Escherichia coli o que pode explicar seu uso popular na disenteria, diarréia e infecções intestinais (Almeida, 1993). A importância desta planta levou sua inclusão na primeira edição da Farmacopéia Brasileira (Brandão et al., 2006).

Apesar de alguns estudos já realizados, os efeitos tóxicos dos extratos de $A$. satureioides são pouco conhecidos (Rivera et al., 2004). Estudos fitoquímicos têm demonstrado que os flavonóides quercetina, 3-Ometilquercetina e luteolina são os constituintes mais significativos extraídos por etanol das inflorescências (Ferraro et al., 1981; Simões et al., 1984), além de ácidos caféicos, clorogênicos, isoclorogênicos e glicolipídios terem sido reportados nas partes aéreas (Broussalis et al., 1989; Mendes et al., 2006). Os extratos aquosos de marcela foram testados para a presença de atividade genotóxica em microrganismos por Vargas et al. (1990), e os resultados positivos foram relacionados à presença da quercetina e do ácido caféico nesses extratos.

Devido a este intenso uso de plantas medicinais, estudos de toxicidade e mutagenicidade são necessários por contribuírem para sua utilização segura e eficaz. $\mathrm{O}$ índice mitótico e índice de replicação são usados como indicadores de proliferação adequada das células (Gadano et al., 2002), o que pode ser medido através do sistema teste vegetal de Allium cepa. O método da aberração cromossômica em raízes de Allium é validado pelo Programa Internacional de Segurança Química (IPCS, WHO) e o Programa Ambiental das Nações Unidas (UNEP) como um eficiente teste para análise e monitoramento in situ da genotoxicidade de substâncias ambientais (Cabrera; Rodriguez, 1999; Silva et al., 2004).

O objetivo do presente trabalho foi avaliar o efeito anti-proliferativo de infusões de $A$. satureioides sobre o ciclo celular de Allium cepa em diferentes anos de coleta.

\section{MATERIAL E MÉTODOS}

\section{Coleta das plantas}

As inflorescências in natura de $A$. satureioides foram coletadas no Rio Grande do Sul, Brasil, na estrada municipal de acesso ao Distrito de Boca do Monte, município de Santa Maria, junto a entrada lateral da Estação Experimental de Silvicultura de Boca do Monte, com localização geográfica definida pelas Lat $(\mathrm{DMS})=29^{0} 37^{0} 60 \mathrm{~S}$ e Long $(\mathrm{DMS})=53^{0} 55^{\prime}$ 0W. As coletas ocorreram no mês de março, que é o período de florescimento desta planta, nos anos de 2003 e 2005, sendo que as inflorescências coletadas em 2003 permaneceram armazenadas em condições ambientais por cerca de 30 meses. De cada coleta, colocou-se uma amostra testemunha no herbário SMDB (Santa Maria Departamento de Biologia), da UFSM, sob número de registro 9927 e 10033 respectivamente. As plantas foram identificadas pela $\operatorname{Prof}^{\mathrm{a}} \mathrm{Dr}^{\mathrm{a}}$ Thais do Canto-Dorow.

\section{Preparo das infusões}

Inflorescências frescas e secas (das duas coletas) de A. satureioides foram colocadas em água fervente, permanecendo em infusão por 10 minutos, os extratos aquosos foram coados e colocados para esfriar em temperatura ambiente. As infusões foram preparadas em 2 concentrações: $5 \mathrm{mg} / \mathrm{mL}$ (T1) e $20 \mathrm{mg} / \mathrm{mL}$ (T2), sendo a concentração de $5 \mathrm{mg} / \mathrm{mL}$ usualmente utilizada para preparar o chá medicinal. Apesar das inflorescências de marcela armazenadas terem perdido água, resultando numa menor massa, a relativa quantidade maior de inflorescências frescas, não foi um parâmetro que possibilitasse alterações nos resultados finais.

Utilizaram-se 3 grupos de 6 bulbos de Allium cepa para cada população de $A$. satureioides, dos anos de 2003 e 2005, cada grupo equivalendo a um dos tratamentos. De cada população foi retirado um grupo de bulbos controle. Todos os bulbos foram colocados em água para enraizarem, após o enraizamento, os mesmos foram transferidos para os extratos que estavam em temperatura ambiente permanecendo por 24 horas, (os bulbos controle foram mantidos em água). A seguir, foram coletadas as radículas com aproximadamente $5-10 \mathrm{~mm}$ de comprimento e fixadas em etanol-ácido acético (3:1) por $24 \mathrm{~h}$. Posteriormente, elas foram retiradas do fixador, mantidas em álcool $70 \%$ e conservadas no refrigerador até o uso.

Efeitos das infusões sobre o ciclo celular de Allium cepa 
Foram feitas em média 5 lâminas por bulbo de cada tratamento e controle de cada população coletada. No preparo das lâminas, utilizou-se 5 radículas por bulbo, ou seja 01 radícula por lâmina, as quais foram hidrolisadas em $\mathrm{HCl} 1 \mathrm{~N}$ por 5 minutos. Foram, então, lavadas em água destilada e coradas com orceína acética $2 \%$. A região meristemática das radículas foi fragmentada com o auxílio de agulhas histológicas, e a lamínula colocada sobre o material (Guerra; Souza, 2002).

Foi feita a análise de 1000 células de cada bulbo, totalizando 6000 células por população. As lâminas foram avaliadas observando-se as células em interfase, prófase, metáfase, anáfase e telófase, com auxílio de microscópio ótico com a objetiva de $40 \mathrm{X}$. O número total de células analisadas por grupo de bulbos foi de 6000 células. Foram calculados os valores médios do número de células de cada uma das fases do ciclo celular de Allium cepa, e determinado o índice mitótico (IM).

\section{Análise estatística}

A análise estatística dos dados foi realizada pelo teste $\chi^{2}$ com nível de probabilidade $<0.05$ foi considerado significativo estatisticamente, utilizando o software estatístico BioEstat 3.0 (Ayres, 2003).

\section{RESULTADOS}

A tabela 1 mostra o número total de células analisadas e o número de células nas diferentes fases do ciclo celular (interfase, prófase, metáfase, anáfase e telófase) nas células das raízes de Allium cepa tratadas com A. satureioides.

Na tabela 2, são apresentados o número total de células analisadas, bem como o número de células que foram observadas em interfase e em diferentes fases da divisão celular durante o ciclo celular de Allium cepa. Nessa mesma tabela, mostra-se também, os valores do índice mitótico e a proporção em porcentagem de células em divisão em relação ao controle.

Para a população de 2003, o índice mitótico das células de Allium cepa diminuiu significativamente após $24 \mathrm{~h}$ em cada concentração do extrato de $A$. satureioides quando comparados com o grupo controle (T1: $\chi^{2}=$ 15.268; T2: $\left.\chi^{2}=194.467\right)$. A redução do índice mitótico também foi significativa quando comparado T1 com T2

Tabela 1. Número de células nas diferentes fases do ciclo celular de células meristemáticas radiculares de Allium cepa tratados com diferentes extratos de $A$. satureioides.

\begin{tabular}{ccccccc}
\hline Populações & Tratamento & Interfase & Prófase & Metáfase & Anáfase & Telófase \\
\hline \multirow{2}{*}{2003} & Controle & 5800 & 32 & 51 & 40 & 77 \\
& T1 & 5870 & 16 & 54 & 0 & 30 \\
\multirow{2}{*}{2005} & T2 & 5996 & 2 & 85 & 0 & 2 \\
& Controle & 5329 & 401 & 48 & 37 & 134 \\
& T1 & 5445 & 381 & 35 & 29 & 59 \\
\hline
\end{tabular}

Tempo de tratamento: Controle $=0 \mathrm{~h}(\mathrm{t}$ zero), Tratamentos: $\mathrm{T} 1, \mathrm{~T} 2=24 \mathrm{~h}$

Concentrações das infusões: T1 = Tratamento $1(5 \mathrm{mg} / \mathrm{mL}), \mathrm{T} 2=$ Tratamento $2(20 \mathrm{mg} / \mathrm{mL})$

Tabela 2. Populações, tratamentos e número de células no ciclo celular (interfase, prófase, metáfase, anáfase, telófase) em pontas de raízes de Allium cepa tratadas com os extratos de A. satureioides.

\begin{tabular}{|c|c|c|c|c|c|c|}
\hline Populações & Tratamento & $\begin{array}{c}\text { Número Total } \\
\text { de Células }\end{array}$ & $\begin{array}{l}\text { Células em } \\
\text { Intérfase }\end{array}$ & $\begin{array}{l}\text { Células em } \\
\text { Divisão }\end{array}$ & $\begin{array}{c}\text { Índice } \\
\text { Mitótico (\%) }\end{array}$ & $\begin{array}{l}\text { Proporção de } \\
\text { células em } \\
\text { divisão/ } \\
\text { controle (\%) }\end{array}$ \\
\hline \multirow{3}{*}{2003} & Controle & 6000 & 5800 & 200 & $3.45 \mathrm{a}$ & ----- \\
\hline & $\mathrm{T} 1$ & 6000 & 5870 & 130 & $2.21 \mathrm{~b}$ & 35.9 \\
\hline & $\mathrm{T} 2$ & 6000 & 5996 & 4 & $0.05 \mathrm{c}$ & 98.55 \\
\hline \multirow{3}{*}{2005} & Controle & 6000 & 5329 & 671 & $12.59 \mathrm{a}$ & ----- \\
\hline & $\mathrm{T} 1$ & 6000 & 5445 & 555 & $10,19 b$ & 19.1 \\
\hline & $\mathrm{T} 2$ & 6000 & 5679 & 321 & $5,65 c$ & 55.12 \\
\hline
\end{tabular}

Médias seguidas da mesma letra não diferem significativamente ao nível de $5 \%$, pelo teste $\chi^{2}$.

Tempo de tratamento: Controle $=0 \mathrm{~h}(\mathrm{t}$ zero), Tratamentos: $\mathrm{T} 1, \mathrm{~T} 2=24 \mathrm{~h}$

Concentrações das infusões: T1 $=$ Tratamento $1(5 \mathrm{mg} / \mathrm{mL}), \mathrm{T} 2=$ Tratamento $2(20 \mathrm{mg} / \mathrm{mL})$ 
$\left(\chi^{2}=122.630\right)$.

Da mesma forma, a população de 2005, percebeuse uma redução do T1 e T2 quando comparados com o grupo controle $\left(\chi^{2}=12.224\right.$ e $\left.\chi^{2}=134.616\right)$ e quando comparados os dois tratamentos $\left(\chi^{2}=67.429\right)$.

Para a proporção de células em divisão de $A$. satureioides, salienta-se que houve maior capacidade antiproliferativa dos seus extratos, quando as raízes de Allium cepa foram expostas às infusões das inflorescências armazenadas, chegando a $98.55 \%$ (Tabela 2 ).

\section{DISCUSSÃO}

Apesar da família Compositae (Asteraceae) compreender algumas das mais antigas e mais valorizadas plantas medicinais (Paulsen, 2002), diferentes gêneros desta família apresentam compostos tóxicos como ácidos tanínicos, hidrociânicos, fórmicos e málicos, rutina e furfural (Duke, 2000).

Utilizou-se para a realização deste trabalho o sistema teste vegetal de Allium cepa para avaliar os efeitos dos extratos aquosos de A. satureioides. Os testes de citotoxicidade utilizando sistema teste vegetal in vivo, como o de Allium cepa, estão validados por vários pesquisadores que realizam de forma conjunta teste animal in vitro e os resultados obtidos são similares (Teixeira et al., 2003; Vicentini et al., 2001). Segundo Fikejö (1994) mesmo que o metabolismo vegetal seja diferente, o sistema teste de Allium cepa é um excelente parâmetro de análise citotóxica, além de que a observação da ocorrência de alterações cromossômicas no ciclo celular de $A$. cepa tem sido usada como indicativo para prevenir a população humana sobre o consumo do produto (Vicentini et al., 2001).

É possível que a alta concentração de alguns compostos químicos tenha um efeito (inibitório ou estimulatório) no ciclo celular, como tem sido mostrado para cafeína em Drosophila prosaltans (Itoyama et al., 1997), mefloquina em linfócitos humanos (Grisolia et al., 1995), extratos de Alpinia mutans e Pogostemun heyneanus nas células de raízes de Allium cepa (Dias; Takahashi, 1994) e glauocolide B extraído de Vemonia eremphila Mart. em linfócitos humanos (Burim et al., 1999) (Camparoto et al., 2002).

Os resultados obtidos neste trabalho demonstraram que os extratos aquosos de marcela inibiram significativamente a divisão celular, em ambas as concentrações estudadas nas plantas recém coletadas e nas armazenadas. Isto indica a capacidade anti-proliferativa dos extratos aquosos de marcela, resultados estes que estão de acordo com estudos realizados "in vitro" por Arisawa (1994). Este autor demostrou que os extratos das flores de marcela inibiram em $67 \%$ o desenvolvimento de células cancerosas. Além de demonstrar que estes extratos apresentaram capacidade citotóxica, mas não mutagênica, apesar de que os flavonóides quercetina, luteolina e 3$O$-metilquercetina, os quais são os componentes mais significativos do extrato aquoso de $A$. satureioides não têm sido reportados como tóxicos e estudos realizados em ratos e camundongos demonstraram que o extrato de A. satureioides teve baixa toxicidade (Rivera et al., 2004; Simões et al., 1988; De Souza et al., 2002; Duke, 2000).

A atividade de inibição enzimática atribuída à presença de taninos é provavelmente responsável pela inibição da divisão celular em células meristemáticas de Allium cepa (Teixeira et al., 2003). É possível, considerar-se então, que a presença destes compostos em A. satureioides estejam relacionados à inibição do ciclo celular de Allium cepa observada neste trabalho.

Nossos resultados também demonstraram o efeito do armazenamento das plantas após cerca de 30 meses. A inibição do índice mitótico observado (Tabela 2 ), indica claramente que os extratos feitos das plantas armazenadas tiveram maior capacidade antiproliferativa do que os extratos obtidos com as plantas frescas. Apesar da importância no conhecimento dos efeitos do armazenamento na atividade farmacológica de plantas medicinais, muito poucos trabalhos têm sido conduzidos nesta área no mundo todo (Fennell et al., 2004). Os efeitos da estocagem é espécie-específica, porque a composição química de cada espécie é diferente (Stafford et al., 2005). Silva et al. (1998) demonstraram que algumas incidências de radiações ultravioleta podem produzir reações químicas que aumentam a quantidade de compostos secundários.

Compostos antimicrobianos aparentam ser estáveis ou convertidos em mais compostos ativos durante a estocagem (Stafford et al., 2005). Ácidos linoleico e oleico são os ácidos graxos responsáveis pela atividade antimicrobiana e, portanto, parecem ser estáveis em espécies secas armazenadas em condições de herbário (Eloff, 1999). Exemplares de material de herbário têm sido mostrados por ainda conter outros compostos estáveis como aminoácidos, flavonóides, óleos voláteis e alcalóides (Phillipson, 1982). Embora, no geral, atividade antimicrobiana esteja retida ou melhorada, alguma mudança química de quebra ocorre durante o armazenamento; embora seja espécie específica (Fennell et al., 2004). Todas as plantas estudas por Fennell et al. (2004) mostraram mudanças na composição química após somente 90 dias de armazenamento, com exceção do material bulbo de Eucomis autumnalis.

Entretanto, as plantas usadas para atividade antiinflamatória, entre outras, podem exigir condições especiais de armazenamento ou somente serem usadas quando estão frescas. Estas medidas particularmente aplicadas para Drimia robusta, onde existiu uma perda total da atividade antiinflamatória nos extratos aquosos após 90 dias de estocagem (Stafford et al., 2005).

É importante salientar que o papel histórico das ervas medicinais no tratamento e prevenção de doenças e seu papel como catalizadoras no desenvolvimento de farmacologia não mantém sua segurança para o uso ilimitado pelo público sem informação (Mathews et al., 
1999; Albuquerque; Hanazaki, 2006).

Através de nossos resultados, é possível verificarse a presença de atividade anti-proliferativa e citotóxica desta espécie, indicando seu potencial terapêutico para inibição do ciclo celular. Mais estudos serão necessários para estabelecer a utilização segura desta planta pela população.

\section{AGRADECIMENTOS}

Os autores agradecem a $\operatorname{Prof}^{\mathrm{a}} \operatorname{Dr}^{\mathrm{a}}$ Thais do Canto-Dorow pela identificação botânica das plantas utilizadas neste trabalho.

\section{REFERÊNCIAS}

Adamoli R 1998. Unconventional therapies in HIV infection: a working perspective. XII Natinal Conference ANLAIDS.

Albuquerque UP, Hanazaki N 2006. As pesquisas etnodirigidas na descoberta de novos fármacos de interesse médico e farmacêutico: fragilidades e pespectivas. Rev Bras Farmacogn 16(Supl.): 678-689.

Almeida ER 1993. Plantas medicinais Brasileiras, conhecimentos populares e científicos. São Paulo. Ed. Hemus Ltda., $341 \mathrm{p}$.

Arisawa M 1994. Cell growth inhibition of KB cells by plant extracts. Nat Med 48: 338-347.

Ayres M 2003. Bioestat 3.0 - Aplicações estatísticas nas áreas das ciências biológicas e médicas. Belém: Sociedade Civil Mamirauá, Brasília CNPq, 290 p.

Brandão MGL, Cosenza GP, Moreira RA, Monte-Mor RLM 2006. Medicinal plants and other botanical products from the Brazilian Official Pharmacopoeia. Rev Bras Farmacogn 16: 408-420.

Broussalis A, Ferraro G, Gurni A, Coussio J 1989. Aspectos fitoquímicos de espécies argentinas del género Achyrocline. Acta Farm Bonaerense 8: 11-16.

Burim RV, Canalle R, Lopes JLC, Takahashi CS 1999. Genotoxic action of the sesquiterpene lactone glaucolide B on mammalian cells in vitro and in vivo. Genet Mol Biol 22: 401-406.

Cabrera GL, Rodriguez DMG 1999. Genotoxicity of soil from farmland irrigated with wastewater using three plant bioassays. Mutat Res-Fund Mol M 426: 211-214.

Camparoto ML, Teixeira RO, Mantovani MS, Vicentini VEP 2002. Effects of Maytenus ilicifolia Mart. and Bauhinia candicans Benth infusions on onion root-tip and rat bone-marrow cells. Genet Mol Biol 25: 85-89.

Castro LO, Chemale VM 1995. Manual de identificação e cultivo de plantas medicinais, condimentares e aromáticas. Porto Alegre, Instituto de Pesquisas Agronômicas, p.78.

De Souza KCB, Schapoval EES, Bassani VL 2002. LC determination of flavonoids: separation of quercetin, luteolin and 3-O-methylquercetin in Achyrocline satureioides preparations. J Pharm Biomed Anal 28: 771-777.

Desmarchelier C, Coussio J, Ciccia G 1998. Antioxidant and free radical scavenging effects in extracts of the medicinal herb Achyrocline satureioides (Lam.) DC
("Marcela"). Braz J Med Biol Res 31: 1163-1170.

Dias FL, Takahashi CS 1994. Cytogenetic evaluation of the effect of aqueous extacts of the medicinal plants Alpinia nutans Rose (Zingiberaceae) and Pogostemun heyneanus Benth (Labiatae) on wistar rats and Allium cepa Linn. (Liliaceae) root tip cells. Rev Bras Genet 17: 175-180.

Duarte MCT, Figueira GM, Pereira B, Magalhães PM, Delarmelina C 2004. Atividade antimicrobina de extratos hidroalcoólicos de espécies da coleção de plantas medicinais CPQBA/UNICAMP. Rev Bras Farmacogn 14(Supl. 1): 6-8.

Duke JA 2000. Toxins: their toxicity and distribution in plant genera. In: Handbook of medicinal herbs, pp. 525568.

Eloff JN 1999. It is possible to use herbarium specimens to screen for antibacterial components in some plants. $J$ Ethnopharmacol 67: 355-360.

Falcão HS, Lima IO, Santos VL, Dantas HF, Diniz MFFM, Barbosa-Filho JM, Batista LM 2005. Review of the plants with anti-inflammatory activity studied in Brazil. Rev Bras Farmacogn 15: 381-391.

Fennell CW, Light ME, Sparg SG, Stafford GI, van Staden J 2004. Assessing African medicinal plants for efficacy and safety: agricultural and storage practices. $J$ Ethnopharmacol 95: 113-121.

Ferraro GE, Norbedo C, Coussio JD 1981. Polyphenols from Achyrocline satureioides. Phytochemistry 20: 2053 2054

Fikejö G 1994. Allium Test II: Assesmente of chemical's genotoxic potential by recording aberrations in chromosomes and cell divisions in root tips of Allium cepa L. Environmental Toxicology and Water Quality 9: 235-241

Gadano A, Gurni A, López P, Ferraro G, Carballo M 2002. In vitro genotoxic evaluation of the medicinal plant Chenopodium ambrosioides. L. J Ethnopharmacol 81: 11-16

Garcia GH, Cavallaro L, Broussalis A, Ferraro G, Martino V, Torres R, Coussio J, Campos R 1995. Antiviral activity of Achyrocline flaccida Wein DC aqueous extract. Phytother Res 9: 251-254.

Garcia GH, Cavallaro L, Broussalis A, Ferraro G, Martino V, Campos R 1999. Biological and chemical characterisation of the fraction with antiherpetic activity from Achyrocline flaccida. Planta Med 65: 343-346.

Grisolia CK, Takahashi CS, Ferrari I 1995. In vitro and in vivo tests in humans confirm that the antimalarial drug mefloquine is not mutagenic. Braz J Genet 18: 611615.

Guerra M, Souza MJ 2002. Como observar cromossomos - Um guia de técnicas em citogenética vegetal, animal e humana. 1. Ed. FUNPEC, Ribeirão Preto, p131.

Itoyama MM, Bicudo HEMC, Cordeiro JA 1997. Effects of caffeine on mitotic index in Drosophila prosaltans (Diptera). Braz J Genet 20: 655-657

Lopez P, Broussalis A, Rodríguez M, Coussio J, Ferraro G 1996. Análisis de muestras comerciales de "marcela" (Achyrocline satureioides). Acta Farm Bonaerense 15: 243-249.

Lorenzi H 2002. Plantas medicinais no Brasil: nativas e exóticas cultivadas. Nova Odessa SP, Instituto Plantarum. 
Mathews H, Lucier G, Fisher K 1999. Medicinal herbs in the United States: research needs. Environ Health Persp 107: 773-778.

Mendes BG, Machado MJ, Falkenberg M 2006. Triagem de glicolipídios em plantas medicinais. Rev Bras Farmacogn 16: 568-575.

Paulsen E 2002. Contact sensitization from Compositaecontaining herbal remedies and cosmetics. Contact Dermatitis 47: 189-198.

Pessoa C 2000. Antiproliferative effects of compounds derived from plants of Northeast Brazil Phytother Res 14: 187-191.

Phillipson JD 1982. Chemical investigations of herbarium material for alkaloids. Phytochemistry 21: 2441.

Ritter MR, Sobierajski GR, Schenkel EP, Menth LA. Plantas usadas como medicinais no município de Ipê, RS, Brasil. Rev Bras Farmacogn 12: 51-62.

Rivera F, Gervaz E, Sere C, Dajas F 2004. Toxicological studies of the aqueous extract from Achyrocline satureioides (Lam.) DC (Marcela). J Ethnopharmacol 95: 359362.

Santos ALG, Ripoll D, Nardi N, Bassani VL 1999. Immunomodulatory effect of Achyrocline satureioides (Lam) DC aqueous extracts. Phytother Res 13: 65-66.

Silva GL, Lee IS, Kinghorn AD 1998. Special problems with the extraction of plants. In: Cannell, New Jersey p. 342. R.J.P. (Ed.), Natural Products Isolation: Methods in Biotechnology. Humana Press.

Silva CR, Monteiro MR, Caldeira-de-Araújo A, Bezerra RJAC 2004. Absence of mutagenic and citotoxic potentiality of senna (Cassia angustifolia Vahl.) evaluated by microbiological tests. Rev Bras Farmacogn 14(Supl. 1): $1-3$.

Simões CMO 1984. Investigação químico-farmacológica de Achyrocline satureioides (Lam.) DC. Compositae (Marcela). Porto Alegre, 186p. Dissertação de Mestrado em Farmácia, Curso de Pós Graduacão em Ciências Farmacêuticas da UFRGS, Universidade Federal do Rio Grande de Sul.

Simões CM, Schenkel EP, Bauer L, Langeloh A 1988. Pharmacological investigations on Achyrocline satureioides (Lam.) DC, Compositae. J Ethnopharmacol 22: 281-293.

Stafford GI, Jager AK, van Staden J 2005. Effect of storage on the chemical composition and biological activity of several popular South African medicinal plants. $J$ Ethnopharmacol 97: 107-115

Teixeira RO, Camparoto ML, Mantovani MS, Vicentini VEP 2003. Assessment of two medicinal plants, Psidium guajava L. and Achillea millefolium L. in in vivo assays. Genet Mol Biol 26: 551-555.

Vargas VM, Motta VE, Leitão CA, Henriques JA 1990. Effects mutagenic and genotoxic of extracts aqueous of Achyrocline satureoides on prokaryotic organism. Mutat Res 240: 13-18.

Vendruscolo GS, Rates S, Mentz LA 2005. Dados químicos e farmacológicos sobre as plantas utilizadas como medicinais pela comunidade do bairro Ponta Grossa, Porto Alegre, Rio Grande do Sul. Rev Bras Farmacogn 15: 361-372.

Vicentini VEP, Camparoto ML, Teixeira RO, Mantovani MS 2001. Averrhoa carambola L., Syzygium cumini (L.) Skeels and Cissus sicyoides L.: medicinal herbal tea effects on vegetal and test systems. Acta Scientiarum 23: 593-598. 